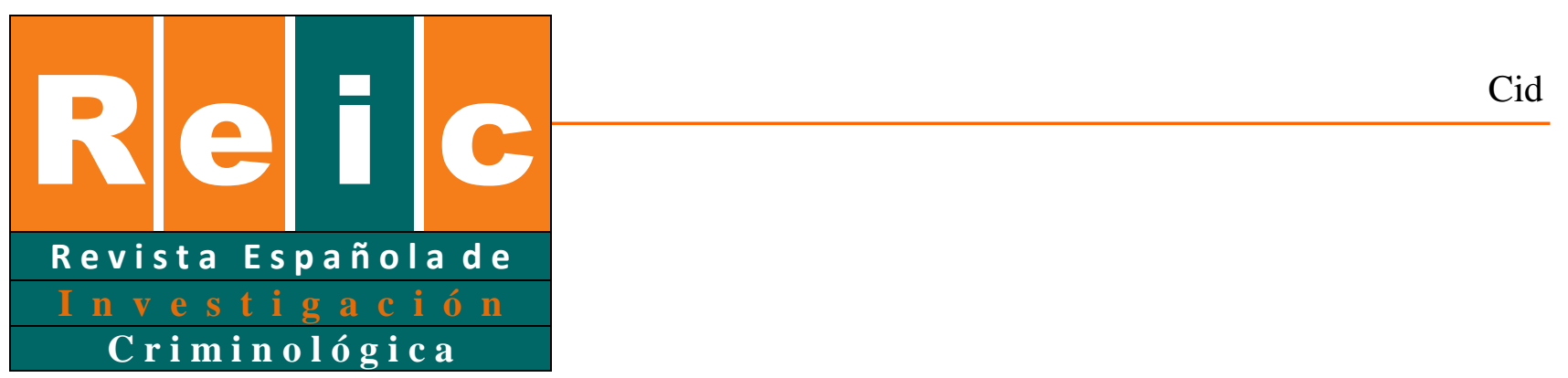

\title{
Editorial
}

José Cid

Editor Jefe REIC

Universidad Autónoma de Barcelona

\section{Balance del 2012 y retos de futuro}

Al abrir el número 11 de nuestra revista me gustaría compartir con los socios de la Sociedad Española de Investigación Criminológica y con los lectores de la revista los resultados del año que cerramos y plantearos los retos de nuestra revista para el futuro.

Durante el año 2012 la revista ha recibido 17 artículos científicos para ser publicados. Como es sabido, las contribuciones son sometidas a un doble proceso de evaluación: en primer lugar, el editor de la revista valora si el artículo resulta coherente con la línea editorial de la revista; superada esta fase, el trabajo, convenientemente anonimizado, es revisado por dos expertos en la materia. Como resultado de este proceso, y teniendo en cuenta los criterios editoriales de la revista (que aparecen explicados en la editorial del n. 10 de la revista), tres artículos han sido aceptados -dos de ellos publicados en el número del 2012 y uno que se publica en el número del 2013-, uno ha sido aceptado con cambios y respecto de dos se ha pedido a los autores que revisen el artículo y lo vuelvan a someter a la revista.

Resulta un deber agradecer a los evaluadores anónimos de la REIC el trabajo intenso que han realizado durante este año. En todos los casos en que se ha producido una evaluación por pares, se ha analizado en profundidad el artículo y se ha realizado una labor constructiva para ayudar a los autores a mejorar su trabajo. Cuando los revisores han aconsejado la no publicación del artículo, lo han justificado ampliamente $\mathrm{y}$, a su vez, han indicado a los autores como superar las objeciones en futuras investigaciones. Es por ello que debe resaltarse la importante tarea de peer-review que realiza la REIC para mejorar la calidad de nuestra investigación criminológica. 
Quería, a su vez, informar de dos modificaciones en el proceso de evaluación de artículos de la REIC. La primera - que fue adoptada en la asamblea de la SEIC celebrada en el congreso de Girona de junio de 2012- consiste en que la opción de no aceptación inicial de un artículo sea tomada de manera colegiada por el editor de la revista y por los editores asociados. De esta manera, se minimizan las posibilidades de que estas decisiones carezcan de justificación suficiente. La segunda -adoptada por el Comité de Redacción de la REIC en su reunión de diciembre de 2012- es que, tanto en la decisión inicial del Consejo Editorial como en la decisión de los evaluadores, exista -junto a las opciones de rechazo, aceptación con cambios y aceptación sin cambios- la opción de que el autor pueda volver a someter el artículo a la revista, exigiendo en tal caso un nuevo proceso de evaluación. Con la citada reforma se dan mayores posibilidades de que los artículos presentados puedan ser publicados.

Pasando a los retos para el futuro, avanzo alguna de las ideas discutidas por la Junta de la SEIC de diciembre de 2012. En primer lugar, los editores de la REIC y su consejo de redacción se han puesto a trabajar para que en un futuro que deseamos que no sea muy lejano nuestra revista pueda pasar a pertenecer al círculo de revistas indexadas en el Journal of Citation Report. No hace falta decir la importancia que tendría para nuestra comunidad científica disponer de una revista incluida en uno de los índices de mayor relevancia internacional. En segundo lugar $-\mathrm{y}$ acogiendo una idea de Juanjo Medina ("La REIC y su impacto", 2012) - nuestra revista debe ser consciente de que su vocación no es la de ser una revista exclusivamente española sino que pretende ser uno de los canales de expresión de la criminología de habla hispana en su conjunto. En este sentido, hemos de dar los pasos necesarios para que la comunidad científica latinoamericana tome a la REIC como una de sus revistas de referencia.

Por último, siendo este posiblemente el reto más importante que tenemos, todos los criminólogos españoles -y ojalá que esto pueda extenderse a los latinoamericanoshemos de mantener y ampliar nuestro compromiso con la REIC y ello pasa porque asumamos que nuestra revista sea destinataria de nuestra mejor investigación. Sólo este compromiso -que se extiende tanto a los investigadores consolidados como a los jóvenes que están comenzando su carrera investigadora en criminología- hará que nos sintamos cada día más orgullosos de nuestra revista. 